\title{
TWO UNUSUAL CASES OF GIANT CELL MYOCARDITIS ASSOCIATED WITH MITRAL STENOSIS AND WITH WEGENER'S SYNDROME
}

\author{
BY \\ P. C. MCCREA AND R. W. CHILDERS \\ From the Departments of Pathology and Cardiology, Royal City of Dublin Hospital, Upper Baggot St., \\ Dublin 4 \\ Received October 8, 1963
}

Inflammation of the myocardium may occur in association with a wide variety of clinical conditions and occasionally occurs as an apparently isolated disorder without demonstrable cause. In some cases of isolated myocarditis, giant cells form part of the inflammatory reaction and the lesion has then been described as "isolated giant cell myocarditis." Giant cell myocardial lesions may occur, of course, in conditions like tuberculosis and sarcoidosis (Saphir, 1960; Forbes and Usher, 1962), which are regularly associated with a giant cell inflammatory reaction.

In this paper, two patients with giant cell myocarditis are described. Though they are unrelated atiologically, both have features of special interest. The first is unusual in that the malady was diagnosed during life from examination of the left atrial appendage removed at mitral valvotomy. Thus an opportunity to correlate, simultaneously, clinical and pathological observations on proven myocarditis was presented.

In the second, giant cell granulomatous myocardial lesions were found at necropsy in a patient who suffered from Wegener's syndrome, a disorder in which granulomatous lesions in the respiratory tract and elsewhere are associated with vascular lesions of polyarteritis type and glomerulitis. Some authors including Wegener himself suggest that this syndrome is a variant of polyarteritis nodosa rather than a separate disease (Wegener, 1939; Harrison, 1960; Heptinstall, 1960). Though cardiac lesions have been described in this illness (Levine and Madden, 1957; Walton, 1958) the chapter written by Saphir (1960) in Gould's Pathology of the Heart does not include Wegener's syndrome in an extensive survey of clinical conditions associated with myocarditis.

\section{CASE Reports}

Case 1. A 37-year-old painter was admitted complaining of effort dyspnœa of five years' duration and occasional hæmoptysis. He had a history of rheumatic fever in childhood. A murmur had first been heard at the age of 23. Three years previously an attack of pleurisy had been accompanied by his first hæmoptysis. He denied ankle swelling, joint pains, or nocturnal dyspnœa.

Physical examination revealed a healthy looking man in no distress and with no evidence of right heart failure. There was no clubbing, cyanosis, or anæmia. The apex was discrete in the normal site. On auscultation the first sound was loud and was preceded by a presystolic murmur. There was a very soft pansystolic apical murmur, an opening snap was present, and P2 was loud. A very few fine râles were heard in the lungs. The urine was normal. Hæmoglobin was $13.8 \mathrm{~g} . / 100 \mathrm{ml}$., total and differential leucocyte counts were normal, erythrocyte sedimentation rate was $7 \mathrm{~mm}$. in one hour (Westergren), and Creactive protein test was positive ++ . The electrocardiogram and chest radiogram showed left atrial enlargement. 


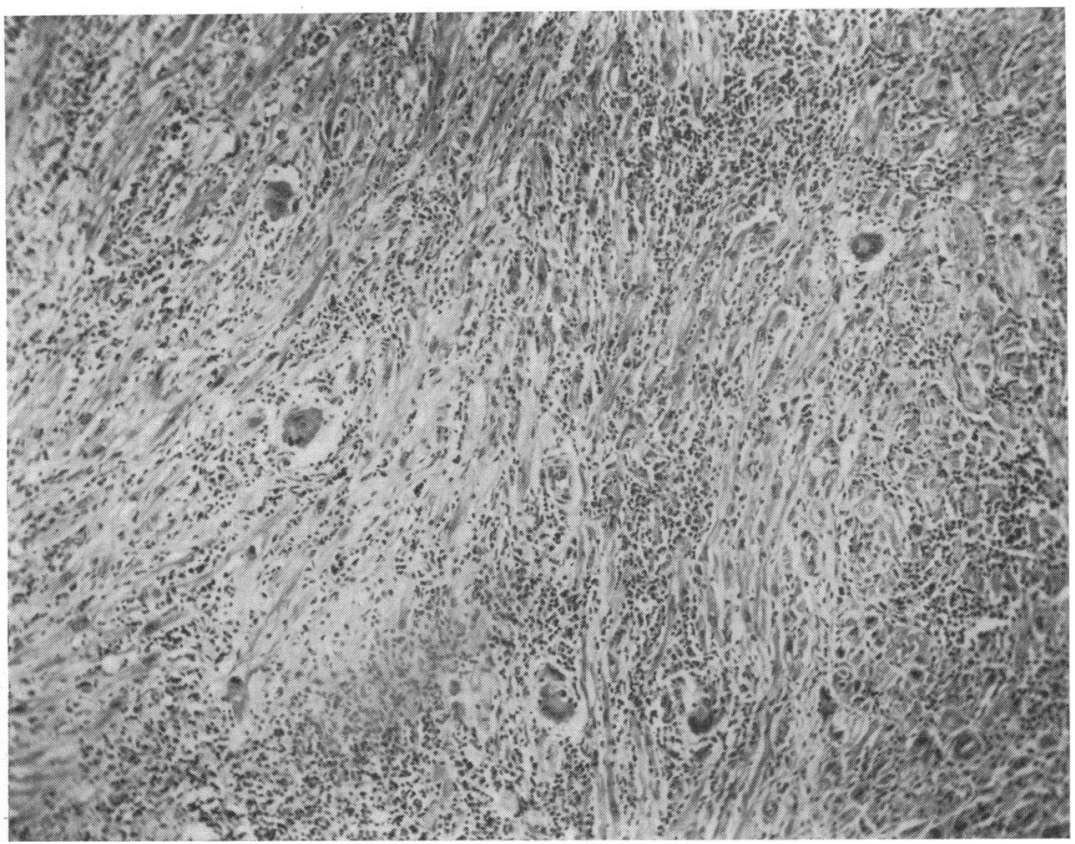

Fig. 1.-Case 1: section of left atrial appendage showing heavy inflammatory cell infiltration with numerous giant cells. (Hæmotoxylin and eosin: $\times 75$.)

Course in Hospital. He complained of recurrent gnawing chest pain of non-specific character. At times he also complained of generalized limb pains. Hæmoptysis occurred on one occasion, and, at this time atrial fibrillation commenced and digoxin was given.

The erythrocyte sedimentation rate was persistently normal $(7,4,7,4 \mathrm{~mm} . / \mathrm{hr}$.) and the C-reactive protein varied from 2 plus to 3 plus positive. The anti-streptolysin titre was 250 units. Throat swab examination revealed no pathogenic organisms.

The patient was given anticoagulants until two days before mitral valvotomy. At thoracotomy the left atrium contained clot, and the appendage was amputated. Moderate mitral stenosis and minimal regurgitation were present. A good split was obtained. Anticoagulants were continued in the post-operative period which was uneventful except for hæmatoma formation in the wound, which had to be aspirated. Three attempts at conversion to sinus rhythm were unsuccessful. At this stage the blood count was within normal limits, the erythrocyte sedimentation rate was normal, and the $\mathrm{C}$-reactive protein was negative.

Following the histological diagnosis, a throat swab was examined and no virus was isolated after four attempted "blind passages" in HeLa cells; faces revealed no virus after four "blind passages" in HeLa cells.

Serological Tests. The dye test and complement-fixation tests for toxoplasmosis were negative. The Wassermann reaction was negative.

Eight months later, the patient was vastly improved in effort tolerance and was working. Fibrillation persisted and was controlled by digoxin. At this time, the blood count was within normal limits, the erythrocyte sedimentation rate was normal, and the C-reactive protein was absent from the serum.

Pathology. The specimen was sectioned transversely to include the whole circumference of the atrial appendage. On section, the cavity was almost completely replaced by firm pale clot. A total of six blocks throughout the entire length of the specimen was taken for microscopic examination.

Microscopical Examination. The myocardium of the atrial appendage showed severe inflammatory change. There was heavy infiltration with lymphocytes, plasma cells, scanty eosinophils, and prominent multinucleated giant cells (Fig. 1). The inflammatory cells were widely dispersed throughout the myocardial fibres and the intermuscular connective tissue septa of the myocardium. Many of the myocardial fibres had disappeared and were replaced by inflammatory cells. Some of the cells were arranged as part of discrete: 
granulomatous foci, but in other areas the cellular infiltrate was diffuse and irregular. Some of the giant cells were of Langhans type, some were of foreign-body type, and some appeared to be of muscle origin. There was no caseation and stains for acid-fast and other bacilli were negative. Stains for fungi were also negative. The epicardium showed much inflammatory change but here no giant cells were seen and the cells were largely lymphocytes. The lumen of the appendage contained an organized thrombus. No typical rheumatic lesions were present, and, as no disease process associated with a specific infectious agent was detected elsewhere in the patient, a diagnosis of chronic giant cell myocarditis of unknown origin was made.

Case 2. A 21-year-old farming boy was admitted complaining of sore throat, painful ankle swelling, and recurrent epistaxis of two weeks' duration. Two years previously he had been turned down by the local defence force because of anæmia which appeared to respond to injections given by his family doctor. Weakness and fatigue had prevented the patient from working for the year before admission. His appetite had diminished but he denied weight loss. Bowel habits, digestion, and sleep were normal. Nocturia had been present for six months.

Physical examination showed a boy of stunted physique in no distress. He was pale and pigmented over forehead and arms, and the fingers were clubbed. Chemosis and pallor of the conjunctiva were present. Fine down was present on the face which had never been shaved. There were sordes on the lips. There was no oral pigmentation. The teeth were carious, the tongue was pale, dry, and atrophic with coating posteriorly. The throat showed a trickle of blood from the posterior nares. The nostrils were full of clotted blood. There were no palpable glands. The axilla was pigmented. Hair growth was normal both there and over the pubis. The radial artery was nodular, the pulse was regular, rate 110/minute, blood pressure $165 / 100$ $\mathrm{mm}$. Hg. The jugular pulse was normal. The apex was hyperdynamic in the normal position. There were no thrills. Triple rhythm was present with a soft hæmic systolic murmur at the apex. There were râles over both Tung bases and over the right chest anteriorly where bronchial breathing was heard. The liver and spleen were both palpable about two finger breadths below the costal margin. The central nervous system was normal. The urine specific gravity never exceeded 1010 during admission, and albumin was present. The temperature and respiratory rate were normal on admission.

Laboratory Tests. Hæmoglobin was $8.1 \mathrm{~g} .100 \mathrm{ml}$. Total leucocyte count: $8000 / \mathrm{c} . \mathrm{mm}$. with a normal differential count. The stained film showed red cells which were microcytic and hypochromic, there was marked anisocytosis, and some distorted forms were present. Examination of the sputum did not reveal any pathogenic organisms. Blood urea was $117 \mathrm{mg} . / 100 \mathrm{ml}$.; total serum protein: $6 \cdot 3 \mathrm{~g} . / 100 \mathrm{ml}$.; albumin: $3.9 \mathrm{~g} . / 100 \mathrm{ml}$.; and globulin: $2.4 \mathrm{~g} . / 100 \mathrm{ml}$. Examination for lupus erythematous cells was negative.

Radiology. The chest film showed patchy consolidation at both bases; skull, knee, and wrist joints were normal.

Course. The patient developed epistaxis on the third day of admission. Mental apathy and confusion became marked. An electrocardiogram showed prolonged QT intervals and non-specific ST-T changes. Antibiotics, cortisone, and repeated calcium injections failed to check a steady deterioration. The blood urea rose to $190 \mathrm{mg}$. $/ 100 \mathrm{ml}$. Tetany was poorly controlled with calcium. The patient died of pulmonary œdema and renal failure on the twelfth day of admission.

Pathology. Necropsy was carried out 12 hours after death. Permission for full examination was not obtained and examination was limited to the thorax and abdominal cavities.

External examination revealed the body of a thin young man. There was clotted blood around the nostrils and the limbs showed light brown pigment.

Examination of the heart showed a large pericardial effusion of yellow fluid with some streaks of fibrin, and the epicardium showed fibrinous pericarditis. The heart was enlarged weighing $430 \mathrm{~g}$. The wall of the left ventricle was moderately hypertrophied. The valves and mural and valvular endocardium were normal. The myocardium of the left ventricle and interventricular septum was slightly pale in some areas.

Microscopical examination of sections from the wall of the left ventricle revealed an organizing fibrinous pericarditis. The epicardium and subepicardial fat showed a dense inflammatory infiltrate consisting of lymphocytes, large mononuclear cells, fibroblasts, occasional neutrophils, and very scanty eosinophils. A few small granulomatous foci with giant cells were also present. Some of the inflammatory lesions were perivascular, and one small arteriole showed acute arteritis with fibrinoid necrosis and mixed inflammatory cellular infiltration of the wall. Another small vessel showed severe fibrinoid change without any inflammatory infiltration. The myocardium showed prominent inflammatory foci which had replaced some of the myocardial fibres and were also involving the intermuscular connective tissue septa of the myocardium 


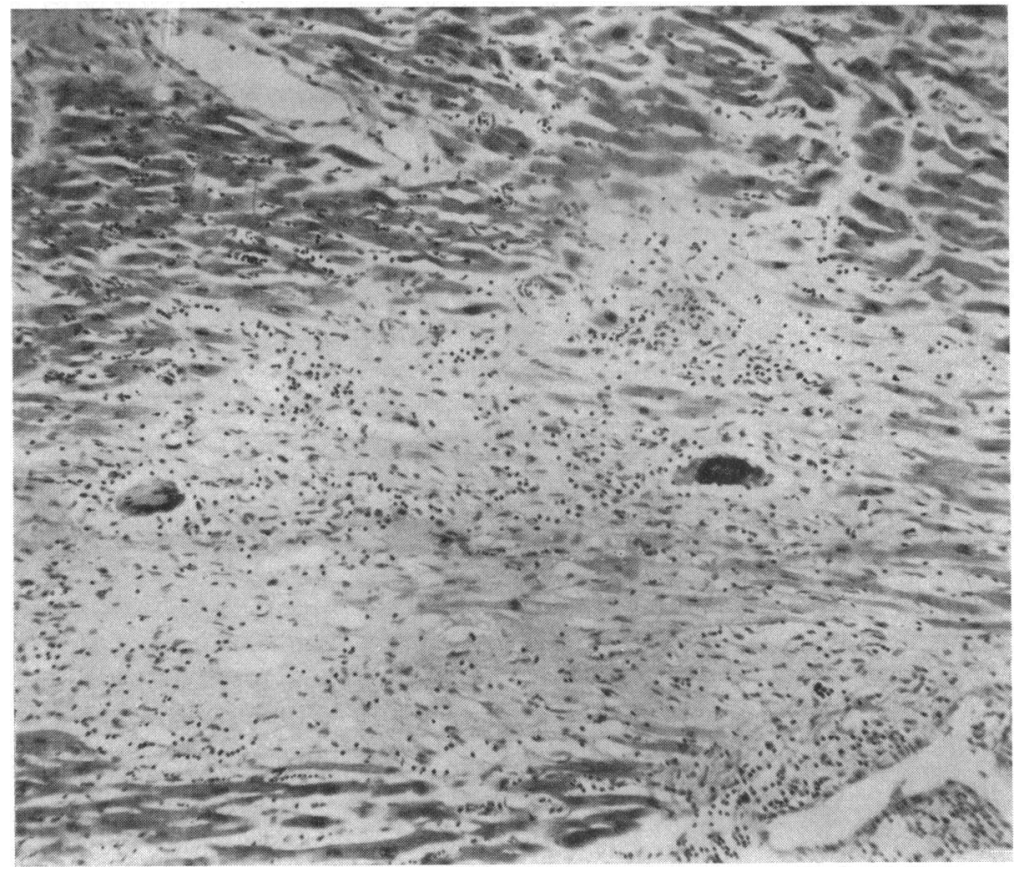

FIG. 2.-Case 2: section of myocardium showing inflammatory exudate with two prominent multinuclea ted giant cells Many myocardial fibres have disappeared. (Hæmotoxylin and eosin: $\times 75$.)

(Fig. 2). Lesions were present in all parts of the myocardium including the subendocardial region. The inflammatory cells included prominent multinucleated giant cells of Langhans type and of foreign body type, numerous round cells, epithelial cells, fibroblasts, and scanty eosinophils. Much of the inflammatory change was diffuse, but there were a number of circumscribed granulomata and some of the inflammatory lesions were perivascular. In the inflammatory areas, muscle fibres had disappeared and some of the residual fibres were necrotic. One coronary arteriole showed necrosis and cellular infiltration of its wall and was surrounded by inflammatory cells. Stains for acid-fast and other bacilli and for fungi were negative.

Respiratory System. The upper respiratory tract was not examined. The trachea and bronchi contained frothy blood-stained fluid but no ulceration was seen. There were dense pleural adhesions on the right side. The left pleural cavity contained a small amount of clear yellow fluid, and there was patchy fibrinous pleural exudate on the surface of the left lung. The lungs were voluminous, felt firm and rubbery in parts, and were mottled, some areas being pale, some areas being dark red. Small firm rounded areas could be felt throughout the lungs especially in the lower lobes. On section there were ædematous areas alternating with firm areas some of which were fibrotic. The right base showed small foci of calcification. The hilar lymph nodes were moderately enlarged.

Microscopical examination of the lungs showed diffuse inflammatory change with large numbers of inflammatory cells, largely round cells, with scanty eosinophils, and sometimes fibroblastic proliferation. In addition there were numerous discrete granulomatous foci often with prominent giant cells of Langhans and foreign body type, mononuclear cells, lymphocytes and sometimes central necrosis, but no typical tuberculous lesions were present. No active vascular inflammation was seen, but a number of small vessels were thrombosed. Staining by appropriate methods did not reveal any micro-organisms.

Kidneys. The kidneys were enlarged, their combined weights being $400 \mathrm{~g}$. There were slight capsular adhesions and the underlying surfaces showed numerous small hæmorrhages. On section the cortex in each case was pale and thinned, the medulla was dark red and appeared normal in each organ. The pelves, renal arteries and veins were normal.

Microscopical examination of the kidneys showed that in both there was severe vasculitis affecting many small arteries and veins of various sizes. The vascular changes were of polyarteritis type, consisting of severe fibrinoid necrosis of the vessel wall with surrounding inflammatory reaction, the cells being mostly 
round cells. Some vessels showed hæmorrhage into their walls, and some were thrombosed. In some places the affected vessels were surrounded by granulomatous lesions without giant cells. Veins as well as arteries were affected, but the lesions were focal, not all vessels being affected. In some instances the inflammatory changes were segmental, only part of the vessel wall being affected.

Some glomeruli showed hyalinization of the loops, some showed proliferation of the cells of Bowman's capsule with early crescent formation and adhesions, but many appeared normal. A number of granulomatous foci without necrosis were present throughout the kidney. The tubules were normal.

Other Organs. Discrete granulomata were present in the liver, adrenals, and hilar glands, but no vascular lesions were seen in these organs. The spleen showed slight hyalinization of arterioles but no other vascular lesions were present. The left radial artery showed calcification of the intima and part of the media.

\section{Discussion}

The development of methods for the surgical correction of deformities of the mitral valve has afforded an opportunity for examination of the left atrial appendage removed at operation. It is thus possible to study cardiac tissue during life and to correlate, simultaneously, clinical and pathological observations. There have been numerous reports of Aschoff bodies and structures resembling those in atrial appendages removed for the relief of mitral stenosis (Kuschner et al., 1952; McKeown, 1953; Lannigan, 1959). Biopsy reports on cardiac diseases other than reactivated rheumatic fever, however, are few. Adickes, Zimmermann, and Cardwell (1951) described the first case of myocardial sarcoidosis diagnosed during life. The diagnosis in this case was subsequently confirmed at necropsy. Zeeman et al. (1962) described an interesting case of granulomatous myocarditis in which the lesion was diagnosed microscopically during life. The patient was a boy aged 16 years who suffered from a ventricular aneurysm which was successfully excised with the aid of cardiopulmonary bypass. A granulomatous giant-cell myocarditis was found on microscopic examination of the tissue removed at operation. In the absence of any causative agent, Zeeman et al. classified this lesion as chronic focal granulomatous myocarditis of unknown ætiology and were uncertain whether this myocarditis had directly caused the aneurism or whether it represented a response to a previous injury to the myocardium. A year after the operation and diagnosis of myocarditis the patient's general condition was good, he had returned to school and to a generally normal existence.

Giant cell myocarditis may occur in association with primary cardiac amyloidosis, syphilis, sarcoidosis, coccidioidomycosis, blastomycosis, torulosis, histoplasmosis, and sarcosporidiosis. Though stains for fungi were negative in the present case, this does not exclude the diagnosis of a deep-seated fungus infection in which the organisms may not be readily seen (Collyns, 1959). Paulley et al. (1956) described myocarditis resulting from toxoplasmosis, the diagnosis being based on positive serological agglutination and complement-fixation tests. In the present case those tests were negative. Tuberculosis and syphilis are unlikely ætiological agents, and trichiniasis is an improbable cause in the absence of other manifestations of the disease, e.g. periorbital œdema and blood eosinophilia. Sarcoidosis cannot be discounted as a possible cause despite the absence of other manifestations of the disease. A recent publication suggests that giant cell myocarditis may be of rheumatic origin (Zschoch, 1961). This report describes a 15-year-old boy who suffered from rheumatic pancarditis with combined aortic-mitral disease. At necropsy there was endocarditis of the aortic and mitral valves, epicarditis, and granulomatous myocarditis. The author, on the basis of the clinical and pathological findings, suggested that granulomatous giant cell myocarditis was of rheumatic origin. However, Decker, Hawn and Robbins (1953) who examined the left atrial appendage in 183 cases of mitral valvotomy, and Lannigan (1959) who made a detailed study of 125 similar specimens, did not mention lesions of the type found in the present case. If giant cell myocarditis is of rheumatic origin it must be a very unusual manifestation of the disease.

Many agents have been proposed as possible causes of myocarditis in which the ætiology is not obvious. Viral infections (Covey, 1942; Marcuse, 1947; Schmidt, 1948), drug hypersensitivity, bacterial infections, vitamin deficiency, and allergy (Marcuse, 1947; Saphir, 1960) have all been put 
forward as possible causative agents. Chronic myocarditis is common in Venezuela and has been studied by Jaffé (1944) and Gould (1960). In some of the cases, giant cell granulomatous myocardial lesions were present. The cause of this myocarditis is not clear. Jaffé believed that an allergic mechanism was responsible. Many of his cases were associated with syphilis, schistosomiasis, and ancylostomiasis. He postulated that, as a result of many conditions including these infections, myocardial fibres were injured and became sensitized to products of myocardial degeneration. Thus any one of a number of agents could sensitize the myocardium so that subsequent damage would release auto-antibodies and induce an inflammatory reaction in the heart. Gould (1960), while forming no definite conclusion about the cause of chronic myocarditis in Venezuela, thought that Jaffe's allergic hypothesis was worthy of serious consideration. In addition he felt that Chagas' disease or a virus or both in combination were possible agents. The possibility that some types of myocarditis may have an immunological basis is supported by evidence from homograft experiments. Thus Bing et al. (1962) found granulomatous myocardial lesions in certain homografted canine hearts. The lesions were strikingly similar to the proliferative stage of rheumatic fever and histochemical examination suggested that antibodies had been produced.

Saphir (1960) described isolated myocarditis as a condition not accompanied by pericarditis and, amongst other things, stated that there was no history of rheumatic fever. Thus Case 1 fails to fulfil Saphir's criteria strictly in that there was a history of rheumatic fever and that the epicardium showed microscopical evidence of inflammation. The myocardial lesions in our case, however, do resemble those described by Kean and Hoekenga (1952), Collyns (1959), and Saphir (1960) in cases of isolated giant cell myocarditis. However, this diagnosis can only be a presumptive one during life as lesions in other organs cannot be absolutely ruled out. Furthermore, Saphir (1960) has emphasized how causative agents of myocarditis may be overlooked, even with post-mortem examinations. In one of his cases, the myocardial lesions resembled those seen in isolated myocarditis. Only the discovery of trichinæ in the diaphragm prevented this particular case from being classified as one of isolated myocarditis. We feel, therefore, that our first case is best classified as giant cell myocarditis of unknown origin.

Godman and Churg (1954) laid down the following pathological criteria for the diagnosis of Wegener's syndrome:

1. Necrotizing granulomatous lesions in upper or lower respiratory tract.

2. Focal necrotizing vasculitis involving both arteries and veins.

3. Glomerulitis.

The pathological lesions in our second case included granulomatous lesions in the lung and other organs, vascular lesions in the kidney and heart, and glomerular and periglomerular lesions. Despite the lack of evidence of involvement of the upper respiratory tract, our case appears to fall into the category of Wegener's syndrome which is considered by a number of authors to be merely a variant of polyarteritis nodosa (Rose and Spencer, 1957; Harrison, 1960; Heptinstall, 1960). Rose and Spencer (1957) studied 104 cases of polyarteritis nodosa and divided these into two categories, those with and those without pulmonary involvement. The cases in which the lungs were involved showed, in general, pathological lesions in the respiratory tract and other organs similar to those described in Wegener's syndrome, including granulomatous vascular lesions that resembled those seen in our case.

Previous reports on heart involvement in Wegener's syndrome have been made by Godman and Churg (1954), Levine and Madden (1957), Walton (1958), and Budzilovich and Wilens (1960). Godman and Churg described cardiac lesions in two of their seven cases. In one, apart from the mitral valve which showed fibrinoid change and leucocyte infiltration, the heart showed no change. In the second, there was superficial granulomatous inflammation of the proximal part of the mitral valve and epicardium. The myocardium showed foci of acute necrotizing coronary arteritis and small collections of mononuclear cells somewhat suggestive of Aschoff bodies. Levine and Madden (1957) reported a single case of Wegener's syndrome in which there was severe cardiac involvement. 
In this patient, the heart was enlarged, the myocardium was soft, and both ventricles were dilated. The endocardial surface of the left atrium was coated with irregular, slightly raised yellowish-grey plaques varying from $2-5 \mathrm{~mm}$. in diameter. Microscopically the heart showed a fibrinous epicarditis, and an inflammatory infiltrate, composed of neutrophils, eosinophils, plasma cells, and large mononuclear cells, was present in the subepicardial fat and in the interstitial tissue of the myocardium. The mural and valvular endocardium of the left atrium showed focal fibrinoid degeneration of collagen, polymorph infiltration, and minute verrucx corresponding to the grossly visible endocardial plaques. Coronary arteries and veins showed endothelial inflammation similar to that of the endocardium. Walton (1958) reviewed 54 cases of Wegener's syndrome collected from published papers and from his own material. Granulomatous lesions in the heart were present in six instances, whereas focal necrotizing arterial cardiac lesions were present in 15 . In the case described by Budzilovich and Wilens (1960), more or less similar lesions to those described by previous authors were present in the mitral valve: the myocardium, however, showed only a few ill-defined, interstitial infiltrates of neutrophils and lymphocytes. An occasional small cardiac vein showed segmental inflammation of the wall.

In polyarteritis nodosa, cardiac̀ lesions have been described by a number of authors (Davson, Ball, and Platt, 1948; Rose and Spencer, 1957). The heart lesion in one case of polyarteritis, described by Davson et al., was a diffuse interstitial myocarditis, inflammatory cells being largely neutrophils. Rose and Spencer (1957) described granulomatous lesions as distinct from vascular lesions, in the heart in only two cases in their large survey of polyarteritis nodosa. In contrast, 34 of their 84 cases showed vascular lesions in the heart. In the two cases in which granulomatous inflammation was present, the lesions were subendocardial. In our own case, lesions were present in the epicardium and diffusely throughout the myocardium to the subendocardial region. Macroscopically, the heart was enlarged and there was epicarditis, but no macroscopic valvular lesions were present and microscopic examination of the valve was not made.

The cause of Wegener's syndrome, like that of polyarteritis nodosa, remains unknown. Godman and Churg (1954) have suggested that in Wegener's syndrome the respiratory tract may present the primary site of attack of some toxic agent, probably microbial, that causes a localized granulomatous reaction. Following this a high degree of local tissue hypersensitivity eventually develops. Generalized hypersensitivity to the offending agent later results in dissemination of the lesions. With regard to this theory, it is interesting to recall a case of penicillin hypersensitivity described by Waugh (1952), in which giant cell myocarditis, arteritis, and visceral granulomata were present. The lesions, apart from much eosinophilic infiltration, were not unlike those present in our case of Wegener's syndrome.

The outstanding clinical manifestations of the cases described as isolated myocarditis are progressive myocardial failure with a weak rapid pulse, low arterial pressure, and an increase in the area of cardiac dullness. Electrocardiographic changes are often seen, and præcordial pain may be present. The disease often occurs in young people and may be present in an apparently healthy patient who suddenly develops progressive myocardial weakness and may quickly die (Saphir, 1960). Unexpected death is common in isolated myocarditis as in the cases reported by Saphir (1942) and Moritz and Zamcheck (1946). In our first case, the diagnosis of myocarditis was unsuspected clinically, although, before operation, C-reactive protein was persistently present in the patient's serum. The significance of a positive C-reactive test as evidence of active myocardial disease is somewhat doubtful according to Elster and Wood (1955) who were unable to correlate $\mathrm{C}$-reactive protein values with the finding of microscopical evidence of active rheumatic disease in the left atrial appendage of patients who had mitral commissurotomy. In our case the clinical manifestations and post-operative course of the patient did not differ substantially from those of other patients undergoing valvotomy for mitral stenosis. The inflammatory process in our case was so severe that one feels it must have been localized, as a diffuse myocardial inflammation of such severity would scarcely be consistent with survival.

In our second case, the clinical picture was dominated by the primary disease, and involvement 
of the myocardium was recognized only at autopsy. Most patients with Wegener's syndrome die rapidly, the average course being about five months, although a few cases may survive for periods up to four years. Death is usually due to renal or respiratory failure (Walton, 1958). The findings in the present case and others discussed above indicate that cardiac lesions involving endocardium or pericardium may occur in Wegener's and related syndromes and may sometimes be an outstanding feature, as in the case described by Levine and Madden (1957).

\section{SUMMARY}

Two cases of giant cell myocarditis are described. In the first patient, the diagnosis was made during life from examination of the left atrial appendage removed at valvotomy for the relief of mitral stenosis. In the absence of an obvious cause, the lesion was regarded as chronic myocarditis of unknown origin.

In the second, giant cell myocarditis was present in association with Wegener's syndrome.

The patients were under the care of Professor V. M. Synge and Mr. Keith Shaw to whom we are indebted. Dr. Jesse Edwards and Dr. J. E. Morison kindly gave opinions on the sections from Case 1, and Dr. Ira Gore, Professor R. A. Q. O'Meara, and Dr. N. Jaswon commented on the histology of both cases. Professor F. S. Stewart carried out the virological studies and Dr. G. B. Ludlam performed the serological tests for toxoplasmosis.

\section{REFERENCES}

Adickes, G. C., Zimmerman, S. L., and Cardwell, E. S., Jr. (1951). Sarcoidosis with fatal cardiac involvement. Ann. intern. Med., 35, 898.

Bing, R. J., Chiba, C., Chrysohou, A., Wolf, P. L., and Gudbjarnason, S. (1962). Editorial. Transplantation of the heart. Circulation, 25, 272.

Budzilovich, G. N., and Wilens, S. L. (1960). Fulminating Wegener's granulomatosis. Arch. Path., 70, 653.

Collyns, J. A. H. (1959). Isolated granulomatous myocarditis. Amer. Heart J., 58, 630.

Covey, G. W. (1942). Acute isolated myocarditis (Fielder's myocarditis). A case report. Amer. J. clin. Path., 12, 160.

Davson, J., Ball, J., and Platt, R. (1948). The kidney in periarteritis nodosa. Quart.J. Med., n.s., 17, 175.

Decker, J. P., Hawn, C. Van Z., and Robbins, S. L. (1953). Rheumatic "activity" as judged by the presence of Aschoff bodies in auricular appendages of patients with mitral stenosis, 1. Anatomic aspects. Circulation, 8,161 .

Elster, S. K., and Wood, H. F. (1955). Studies of C-reactive protein in patients with rheumatic heart disease. 1. Lack of correlation between C-reactive protein and Aschoff bodies in left auricular appendage biopsies. Amer. Heart J., 50, 706.

Forbes, G., and Usher, A. (1962). Fatal myocardial sarcoidosis. Brit. med. J., 2, 771.

Godman, G. C., and Churg, J. (1954). Wegener's granulomatosis, pathology and review of the literature. A.M.A. Arch. Path., 58, 533.

Gould, S. E. (1960). Geographic pathology. Chronic myocarditis of Venezuala. Amer. J. Path., 36, 533.

Harrision, C. V. (1960). In Recent Advances in Pathology, 7th ed. Churchill, London.

Heptinstall, R. H. (1960). Diseases of the kidney. In Recent Advances in Pathology, 7th ed., ed. C. V. Harrison, p. 87. Churchill, London.

Jaffé, R. (1944). General considerations on pathogenesis: syphilitic aortitis myocarditis, hepatic cirrhosis. J. Lab. clin. Med., 29, 139.

Kean, B. H., and Hoekenga, M. T. (1952). Giant cell myocarditis. Amer. J. Path., 28, 1095.

Kuschner, M., Ferrer, M. I., Harvey, R. M., and Wylie, R. H. (1952). Rheumatic carditis in surgically removed auricular appendages. Amer. Heart J., 43, 286.

Lannigan, R. (1959). The rheumatic process in the left auricular appendage. J. Path. Bact., 77, 49.

Levine, H., and Madden, T. J. (1957). Wegener's granulomatosis: report of a case. Amer. Heart J., 53, 632.

McKeown, F. (1953). The left auricular appendage in mitral stenosis. Brit. Heart J., 15, 433.

Marcuse, P. M. (1947). Non-specific myocarditis. Analysis of a series of 36 cases. Arch. Path., 43, 602.

Moritz, A. R., and Zamcheck, N. (1946). Sudden and unexpected deaths of young soldiers. Arch. Path., 42, 459.

Paulley, J. W., Jones, R., Green, W. P. D., and Kane, E. P. (1956). Myocardial toxoplasmosis. Brit. Heart J., 18, 55.

Rose, G. A., and Spencer, H. (1957). Polyarteritis nodosa. Quart. J. Med., n.s., 26, 43.

Saphir, O. (1942). Isolated myocarditis. Amer. Heart J., 24, 167. Illinois.

Schmidt, E. C. H. (1948). Virus myocarditis. Pathologic and experimental studies. Amer. J. Path., $24,97$. 
Walton, E. W. (1958). Giant-cell granuloma of the respiratory tract (Wegener's granulomatosis). Brit. med. J., 2, 265.

Waugh, D. (1952). Myocarditis, arteritis, and focal hepatic, splenic, and renal granulomas apparently due to penicillin sensitivity. Amer. J. Path., 28, 437.

Wegener, F. (1939). Über eine eigenartige rhinogene granulomatose mit besonder betieligung des arterienystems und der nieren. Beitr. path. Anat., 102, 36.

Zeeman, S. E., Templeton, J. Y., Goldburgh, W. P., and Aponte, G. (1962). Ventricular aneurysm. Report of a case occurring in a 16-year-old boy with granulomatous myocarditis. Amer. Heart J., 63, 270.

Zschoch, H. (1961). Beitrag zur Pathogenese der granulomatösen Riesenzellmyokardites. Zbl. allg. Path. path. Anat., 102, 132. 